\title{
TRAJETÓRIA DA INDÚSTRIA TÊXTIL EM ALAGOAS E SERGIPE: ENTRE O DECLÍNIO E A MODERNIZAÇÃO
}

\author{
Bruno Bianchi Gonçalves da Silva \\ Universidade Federal de Alagoas \\ Mestre em Geografia \\ bruno bianchi1@hotmail.com \\ Domingos Sávio Corrêa \\ Universidade Federal de Alagoas \\ Professor do Programa de Pós-Graduação em Geografia \\ saviocorrea642@gmail.com
}

\begin{abstract}
RESUMO
De forte tradição têxtil, os estados de Alagoas e Sergipe apresentam realidades opostas sobretudo a partir dos anos 2000. Alagoas enfrentou o declínio de seu parque têxtil nas décadas recentes ao passo que Sergipe se reestruturou neste setor. Assim, a pesquisa tem por objetivo identificar os principais fatores do declínio do parque têxtil alagoano, à medida que, em Sergipe ocorre a reestruturação do parque têxtil, e considerar as motivações na instalação de fábricas têxteis em determinadas cidades sergipanas. A escolha em estudar ambos os estados sob a perspectiva têxtil não foi aleatória. Trata-se de estados vizinhos com porte socioeconômico semelhante e um processo histórico que permite algumas aproximações. Analisando em perspectiva histórica, o início do século XXI marca o recorte temporal da pesquisa. Por se tratar de um setor industrial complexo a pesquisa se detêm as fábricas têxteis de fiação e tecelagem, não descartando empresas verticalmente integradas, isto é, que integram as etapas produtivas de beneficiamento das fibras à produção de determinado artigo têxtil. Constata-se que o desinteresse da elite política alagoana pela indústria têxtil e a resistência a modernização condicionou o declínio do parque têxtil e inviabilizou a atração de novas empresas do setor.
\end{abstract}

Palavras-chave: Industrialização. Nordeste. Parque Têxtil. Algodão.

\section{TRAJECTORY OF THE TEXTILE INDUSTRY IN ALAGOAS AND SERGIPE: BETWEEN DECLINE AND MODERNIZATION}

\begin{abstract}
With a strong textile tradition, the states of Alagoas and Sergipe present opposing realities, especially since the 2000s. Alagoas faced the decline of its textile park in recent decades, while Sergipe restructured in this sector. The aim of this research is to identify the main factors in the decline of the Alagoas textile park, as the textile park is being restructured in Sergipe, and to consider the motivations for the installation of textile factories in certain Sergipe cities. The choice in studying both states from the textile perspective was not random. These are neighboring states with similar socioeconomic status and a historical process that allows for some approximations. Analyzing in historical perspective, the beginning of the XXI century marks the temporal cut of the research. Due to the fact that it is a complex industrial sector, the spinning and weaving textile mills are not in the process of being abandoned, and that they do not rule out vertically integrated companies, that is, they integrate the productive stages of processing the fibers into the production of a particular textile article. It is observed that the disinterest of the Alagoas political elite by the textile industry and the resistance to modernization conditioned the decline of the textile park and prevented the attraction of new companies of the sector.
\end{abstract}

Keywords: Industrialization. Northeast. Textile Park. Cotton.

\section{INTRODUÇÃO}

Analisando as fábricas têxteis de fiação e tecelagem, especialização produtiva da região Nordeste no setor têxtil, a pesquisa tem por objetivo identificar os principais fatores do declínio do parque têxtil alagoano, 
paralelo ao movimento de reestruturação do parque têxtil de Sergipe, bem como, considerar as motivações na instalação de fábricas têxteis em determinadas cidades sergipanas.

A análise da trajetória das fábricas têxteis em Sergipe revela um parque têxtil com grande diversificação, envolvendo desde empresas especializadas em determinada etapa produtiva (fiação, tecelagem, malharia ou acabamento), até empresas verticalmente integradas, abrangendo todas as etapas produtivas. Diante da abertura econômica nacional dos anos 1990, que não privilegiou a indústria nacional, é observado como principal reação do setor têxtil à concorrência com produtos estrangeiros, a verticalização da produção e as fusões ou aquisições entre empresas. Possibilitando assim, maior agilidade nas adequações da linha de produção e redução de custos entre as etapas produtivas.

As transformações na estrutura macroeconômica brasileira nos anos 1990, forçaram uma nova dinâmica espacial no setor têxtil cuja as ações de maior destaque são: a instalação de novas plantas fabris integradas ou o deslocamento dos setores mais intensivos em mão-de-obra (fiação e tecelagem) para o Nordeste, valendo-se da mão-de-obra relativamente mais barata na região. Esses investimentos ocorreram principalmente por capitais oriundos das regiões Sudeste e Sul. Com o objetivo de reduzir custos e concorrer com os produtos têxteis estrangeiros no mercado doméstico, o deslocamento regional de segmentos da produção têxtil, reforçou a especialização produtiva de Sergipe (e também do Nordeste) nos segmentos têxteis de fiação e tecelagem.

A pesquisa aponta, sob a perspectiva do processo histórico, que a presença de um parque têxtil já instalado em Sergipe, contendo fábricas tradicionais que atravessaram sucessivas crises setoriais e econômicas, possibilitou a sua modernização a partir dos anos 2000 via investimentos diretos de empresários do Sul e Sudeste e investimentos destes empresários associados aos investimentos de empresários locais.

Em trajetória contrária seguiu o parque têxtil em Alagoas, declinando lentamente desde a década de 1960 com o fechamento gradativo de grandes e centenárias fábricas de fiação e tecelagem a cada período de crise. Entre os períodos de crise a pesquisa destaca três, sendo eles: $\left.1^{\circ}\right)$ os anos 1960 , após os efeitos da integração econômica regional com a expansão rodoviária da década anterior, possibilitando a entrada de tecidos mais baratos das fábricas do Sudeste no mercado regional, acabando assim, com o monopólio comercial das fábricas têxteis locais; 2) os anos 1980, com a tentativa de recuperação do setor a partir da instalação de fábricas de pequeno porte que não conseguiram afirmação no mercado; 3) os anos 1990, quando o já combalido parque têxtil local enfrenta problemas externos e internos, diante da abertura econômica nacional, a crise fiscal de Alagoas impactando o mercado consumidor local e a devastação das plantações de algodão pela praga do bicudo, eliminando a última vantagem locacional das fábricas têxteis, o acesso barato as fontes de matéria-prima.

O fechamento das últimas fábricas têxteis em Alagoas, paralelo a modernização do parque têxtil em Sergipe nos anos 2000, consuma a trajetória oposta dos estados. O declínio do parque têxtil em Alagoas além de aprofundar a baixa diversidade econômica do estado, deixou uma brecha de mercado, aproveitada parcialmente pelas fábricas têxteis em Sergipe. Essa constatação foi possível através de entrevistas orais com vendedores autônomos e vendedores de lojas sediados em Alagoas, comercializando produtos têxteis oriundos das fábricas do estado vizinho.

Em relação a localização industrial têxtil, as novas fábricas no estado de Sergipe priorizaram municípios com a presença fabril têxtil e localizados estrategicamente, próximos as principais rodovias que cortam o estado. A pesquisa finaliza apontando outros fatores, não desprezíveis, que corroboraram na atração de novas fábricas têxteis para o estado de Sergipe como a inserção de representantes diretos do setor na estrutura política do estado e uma classe média mais numerosa em relação a Alagoas. Nesse aspecto, vale destacar que a produção têxtil brasileira é voltada ao mercado interno, pois, somente $8 \%$ da produção é destinada à exportação (BRADESCO, 2017).

\section{METODOLOGIA}

No âmbito da Geografia Econômica, compõem o referencial teórico da pesquisa teorias que utilizam o método do materialismo histórico para compreender a trajetória do setor têxtil nos estados de Alagoas e Sergipe. Evitando assim, uma visão de fatalismo histórico, ou seja, de uma realidade acabada. Ao contrário, possibilita uma análise da trajetória têxtil nos estados enquanto processo histórico em constante construção, contendo seus avanços, recuos e particularidades.

Desse modo, em conjunto, as teorias de Rangel $(1981$; 2005) Dualidade Básica da Economia Brasileira, Santos (1982; 2008) Formação Socioespacial, e Cholley (1964a; 1964b) Combinações Geográficas, 
permitem a análise do setor têxtil nos estados em questão enquanto processo histórico sob múltiplas determinações (fatores humano, físico e biológico) e não limitada a elementos puramente econômicos. Considerando os múltiplos fatores que atuam no espaço geográfico, dispomos de uma análise integrada entre matéria-prima e indústria. No caso desta pesquisa, entre o algodão e as fábricas têxteis.

Em Rangel (1981; 2005) a teoria da 'Dualidade Básica da Economia Brasileira' ao explicar sistematicamente a realidade brasileira, coloca-se como alternativa aos modelos importados que buscam explicar a visão contrastada do Brasil, um país moderno no litoral e atrasado no interior. Dedica atenção especial à industrialização do país como instrumento essencial na modernização das forças produtivas e elevação do padrão de vida da população. Através de um ciclo cooperativo de tecnificação do campo, absorção da mão de obra rural pela indústria e sofisticação do hábito de consumo. Diagnosticando a formação social brasileira, suas "etapas" são sucedidas pela formação de novos pactos de classes hegemônicas assumindo o comando da vida nacional. Isto ocorre através de meias revoluções, dispensando a participação da base da população no processo revolucionário e impondo relações verticais na sociedade.

A partir da dualidade básica, é observado a influência das classes hegemônicas no comando político em Alagoas e Sergipe sobre o declínio e o avanço do parque têxtil nos respectivos estados. Um fator extraeconômico que não deve ser desconsiderado. Tendo em vista o papel das meias revoluções na sociedade, em Alagoas, ao longo de toda a trajetória do setor têxtil houve a perpetuação dos interesses da elite canavieira na esfera política e econômica, fato que custou caro ao dinamismo do parque têxtil no estado. Com mentalidade agrária e senhorial a elite canavieira do estado é alheia a qualquer interesse de industrialização, fato observado desde a origem do setor têxtil no estado com as primeiras fábricas fundadas por comerciantes de origem portuguesa.

Utilizando a Formação Socioespacial, proposta por Santos (1982; 2008), analisamos os avanços e recuos do setor têxtil repercutindo no espaço, objeto da Geografia. Considerando que as ações sociais precisam de uma base material para se concretizarem, a Formação Socioespacial relega a visão inerte do espaço. Colocando-o dialeticamente como palco e agente das transformações sociais. Desse modo, diante da experiência industrial têxtil, podemos acompanhar a transformação de sociedades pautadas pelo exclusivismo primário-exportador, em sociedades voltadas também ao mercado interno e produzindo bens manufaturados. No caso de Sergipe, observamos como as repercussões do processo industrial têxtil no espaço foram determinantes na reestruturação do parque têxtil no início do século XXI.

As combinações de agentes internos e externos nas transformações da sociedade e sua experiência histórica própria, derivam a unidade e a totalidade de uma sociedade. Através da totalidade, a formação social abrange as esferas econômica, social, política e cultural de uma sociedade (SANTOS, 2008). Ciente desses aspectos, a pesquisa não desconsidera as repercussões da indústria têxtil nacional nos estados de Alagoas e Sergipe e as particularidades na trajetória industrial têxtil nos estados. Mesmo contendo formações sociais semelhantes, cada qual contém um processo histórico particular, a primeira que não se livrou das amarras agrárias levando a derrocada do parque têxtil, enquanto que a segunda, soube aproveitar a tradição fabril têxtil via modernização de seu parque têxtil.

Através das Combinações Geográficas de Cholley (1964a; 1964b) associando os fatos humanos aos fatos naturais nos fornece elementos para uma análise integrada entre 0 algodão e a indústria têxtil, abrangendo todo o processo produtivo do setor. A ação combinada dos elementos humanos, físicos e biológicos explica a ampla presença do algodão no semiárido nordestino, uma planta cultivada desde o tempo pré-colonial pelos indígenas que se adaptou as condições de clima e solo da região.

Cholley (1964a; 1964b) considera a ação humana o centro das atenções e tem por objetivo descobrir o dinamismo de uma combinação, sua extensão espacial e sua sucessão por uma nova combinação. Conforme o autor, nenhuma combinação é eterna, cada uma tem sua gênese, desenvolvimento e declínio. Assim, analisamos o algodão no semiárido nordestino, cultivado principalmente pela pequena produção, como uma combinação geográfica, cujo o auge ocorreu na primeira metade do século XX.

O declínio das áreas tradicionais de cultivo nos anos 1990 e seu deslocamento para o Cerrado marca a sucessão de combinações. Esta última mais moderna, com maior emprego técnico (máquinas e melhoramento genético), cultivada em outras bases (latifúndio e empresariado) e adaptada a diferentes tipos de solo e clima. É justamente a materialização desses fatores sobre uma base geográfica e humana que confere o caráter particular de uma combinação.

No levantamento bibliográfico, buscando responder o porquê das dissensões na trajetória industrial têxtil entre Alagoas e Sergipe, sobretudo no início do século XXI, foi necessário um levantamento histórico a partir de publicações resguardadas por órgãos oficiais e tratamento de dados concernentes a produção

$\begin{array}{lllll}\text { Caminhos de Geografia } & \text { Uberlândia-MG } & \text { v. 21, n. } 77 & \text { Out/2020 } & \text { p. 29-43 Página } 31\end{array}$


têxtil. Na biblioteca da Superintendência do Desenvolvimento do Nordeste (Sudene), em Recife-PE, buscou-se publicações específicas contendo as ações e a participação dos dois estados nos programas de modernização da indústria têxtil regional.

Na pesquisa direta, através de entrevista presencial, foi priorizada a coleta de informações não disponíveis em outros meios com a finalidade de conhecer a conjuntura atual da indústria têxtil em Sergipe e sua inserção no mercado alagoano. Fundamental nessa etapa foram as informações obtidas na Companhia de Desenvolvimento Econômico de Sergipe (Codise) e entre os comerciantes de confecções localizados em Maceió-AL. Ao todo foram cinco entrevistas, envolvendo um economista da Codise, uma vendedora de loja de confecções e três comerciantes de confecções do antigo bairro de Fernão Velho. Um deles, exgerente da extinta Fábrica Carmen, que deu origem ao bairro.

\section{GÊNESE E TRAJETÓRIA DA INDÚSTRIA TÊXTIL EM ALAGOAS E SERGIPE}

Estados vizinhos, inseridos na mesma região, Alagoas e Sergipe guardam um processo histórico e uma base econômica semelhante até a primeira metade do século XX. Tanto o Litoral como o Sertão são marcados por atividades econômicas bastante distintas. Predominando o latifúndio exportador, através da cultura canavieira, no Litoral, e o latifúndio voltado ao mercado interno, tendo como atividade principal a pecuária, no Sertão.

Economias satélites, os estados orbitam entre Pernambuco e Bahia que detêm os principais portos da região. Tanto Aracaju (SE) quanto Maceió (AL), são exemplos de cidades que se desenvolveram a partir da atividade portuária com forte presença dos comerciantes de importação/exportação, fatores que foram decisivos na elevação dessas cidades à capital dos respectivos estados no século XIX (CORRÊA, 1965).

Observar a consolidação do capital comercial nestas cidades é fundamental para compreender o advento das fábricas têxteis. Oriundas do acúmulo de capital no comércio de importação/exportação, os comerciantes portugueses figuram entre os sócios majoritários dessas fábricas. Trazendo consigo a tradição europeia das manufaturas têxteis e o desejo de acumulação, instalam as primeiras fábricas do gênero nos estados.

Em Alagoas, a presença industrial têxtil encerra o exclusivismo açucareiro de mais de três séculos, impulsiona a urbanização e gera transformações sociais e políticas. Com a instalação da Fábrica Carmen, em 1857, utilizando maquinário inglês, inicia-se a produção industrial têxtil, ainda voltada à produção de tecidos grossos para os engenhos locais. Neste período, a proximidade das fontes de matéria-prima e dos meios de transportes são determinantes na localização da planta fabril, daí o seu aspecto de relativo isolamento (Figura 1). Priorizando a proximidade da matéria-prima e transportes, as primeiras fábricas estão mais afastadas do centro urbano (SANT'ANA, 2011).

Figura 1 - Aspecto da Fábrica Carmen no antigo bairro industrial de Fernão Velho em Maceió-AL.

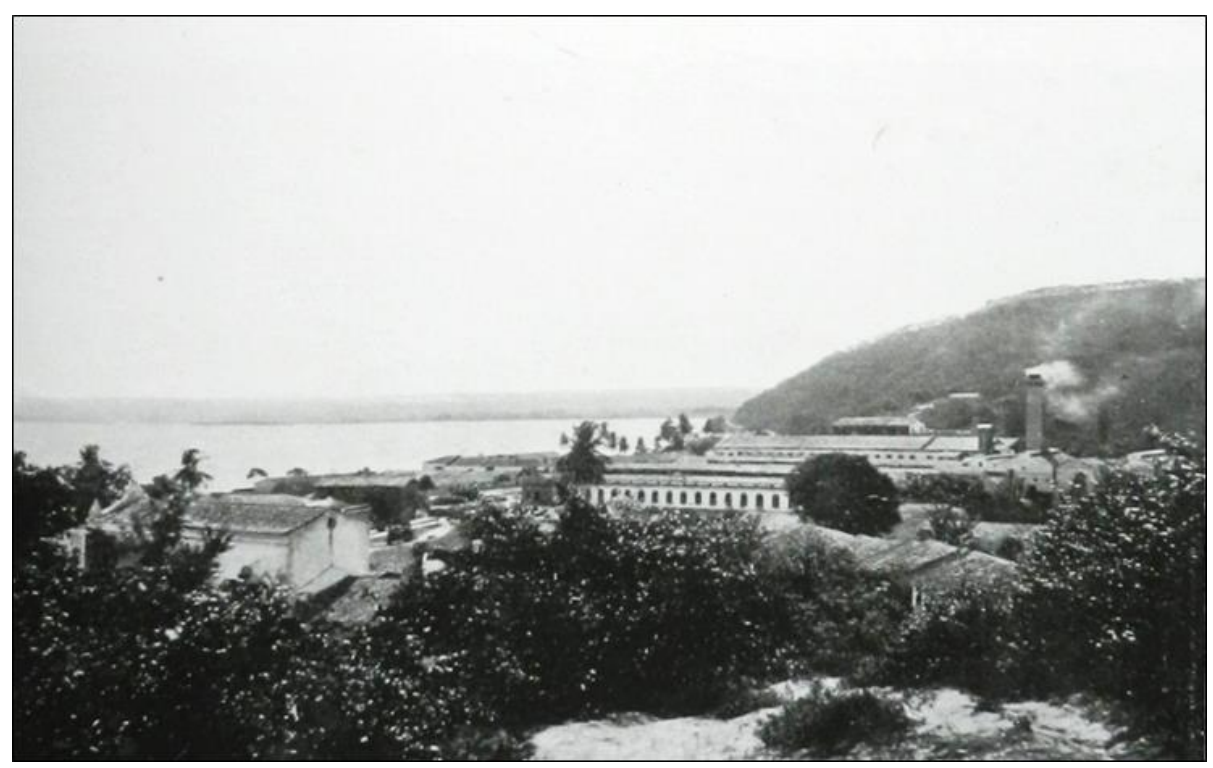

Fonte - MARROQUIM (1922). 
A inserção da indústria têxtil, um elemento tipicamente humano, torna mais complexa a combinação no espaço agrário alagoano. Cultivado inicialmente pelos indígenas para a produção artesanal, na produção do algodão, ainda que sob forte influência dos elementos físicos e biológicos, predomina o elemento humano, uma vez que, os indígenas já haviam domesticado a planta. A partir da presença industrial têxtil, inserindo novas espécies de algodão e as cultivando em ambientes mais propícios, reforça o domínio do elemento humano.

O primeiro boom do setor têxtil alagoano ocorre sob os efeitos do Encilhamento ${ }^{1}$, na transição ImpérioRepública, quando surgem quatro fábricas têxteis. Entre elas, a Cachoeira e a Progresso, responsáveis pela formação da cidade de Rio Largo ao gestar um complexo têxtil no local. Incorporando parcelas da população rural e buscando fixá-las nas proximidades das fábricas, estes empreendimentos são caracterizados pela composição fábrica-vila operária. Além de oferecer uma estrutura de assistência ao trabalhador com ambulatórios, escolas e farmácias. Incorporando os elementos da Primeira Revolução Industrial, essas fábricas são responsáveis pela difusão da energia à vapor no estado, ao utilizá-la como principal matriz energética (TENÓRIO e LESSA, 2013).

Diferente de Alagoas, o período do Encilhamento representa para Sergipe o início da produção têxtil em moldes industriais. Em relativo atraso, seu setor têxtil se expande somente no início do século XX, com a chegada da ferrovia em 1907, cortando o estado de norte a sul e passando pela capital Aracaju. Vale destacar que Alagoas, um estado igualmente periférico, dispõe do transporte ferroviário desde a penúltima década do século XIX. O início do século XX será de intenso desenvolvimento para o setor têxtil sergipano, de modo que, nos anos 1920, atinge o mesmo número de fábricas de Alagoas (Tabela 1) e a supera em número de operários e maquinário (PASSOS SUBRINHO, 1983; SANTOS, 2012).

Atingindo a fase de consolidação, a indústria têxtil coloca-se ao lado da indústria açucareira como principal atividade econômica desses estados. Em Sergipe, juntas, representam 96\% da potência instalada da indústria nos anos 1920. Nesse período, a indústria têxtil local não foi afetada pela crise setorial, recebendo estímulos da exportação para outros estados. Enquanto em 1907 seu mercado externo respondia por $12 \%$ do valor da produção, em 1920 , salta para $27 \%$ de participação (PASSOS SUBRINHO, 1983).

Tabela 1 - Fábricas têxteis por número de operários e teares em Alagoas e Sergipe, 1922.

\begin{tabular}{cccccc}
\hline \multicolumn{2}{c}{ ALAGOAS } & \multicolumn{3}{c}{ SERGIPE } \\
\hline Fábricas & Operários & Teares & Fábricas & Operários & Teares \\
\hline Fábrica Cachoeira & 1.112 & 550 & Sergipe Industrial & 2.175 & 350 \\
Cia. União Mercantil & 850 & 550 & Confiança & 811 & 300 \\
Fábrica Progresso & 810 & 300 & Peixoto Gonçalves & 600 & 250 \\
Fábrica da Pedra & Mais de 800 & - & Santa Cruz & 530 & 300 \\
Fábrica Penedense & 500 & 230 & Industrial São & 374 & 250 \\
Cia. Fiação e Tecidos & 300 & 162 & Cristóvão & & 180 \\
São Miguel & 300 & 120 & Industrial de Propriá & 353 & 180 \\
Fábrica Alexandria & $180^{(1)}$ & - & Empresa Têxtil & 320 & 100 a 120 \\
Fábrica Pilarense & Cerca de & 1.912 & Total & 5.524 & Cerca de \\
\hline TOTAL & 4.852 & & & & 1.930 \\
\hline
\end{tabular}

Nota: (1) Número de operários no ano de 1902.

Fonte - MARROQUIM (1922); ROMÃO (2000); TENÓRIO e LESSA (2013).

${ }^{1}$ O Encilhamento foi uma crise econômica gerada no início da República, resultante da política econômica de livre emissão de créditos, ampliação da atuação bancária e aumento na emissão de papel-moeda, condicionando a formação da bolha de crédito. Não obstante, acelerou a formação de capital através da fundação de fábricas, com destaque ao setor têxtil, responsável pela industrialização do país nesse período (STEIN, 1979). 
As duas Guerras Mundiais trouxeram momentos bastante favoráveis à indústria têxtil, alterando ainda que temporariamente, a posição de Alagoas e Sergipe na divisão internacional do trabalho, passando da condição de primário-exportador a exportador de bens manufaturados quando ocupam brechas no mercado mundial, dominado tradicionalmente pela indústria do centro do sistema. Esse período extremamente favorável resultou na modernização de maquinário, no dobro da produção e na ampliação das instalações das fábricas (TENÓRIO e LESSA, 2013).

Em seu auge nos anos 1940, constam treze fábricas têxteis em cada estado, após Alagoas e Sergipe registrarem os maiores crescimentos, perdendo apenas para Pernambuco, centro têxtil regional da época. Desse modo, Alagoas e Sergipe representam o terceiro e quarto maior operariado, respectivamente, totalizando $32 \%$ das fábricas e $27 \%$ do operariado têxtil do Nordeste (CETEX, 1946).

Com a história do país caracterizada por "meias revoluções", isto é, pelos pactos de classe realizados pelo alto, manteve-se o poder político dos coronéis e das oligarquias locais, perpetuando em Alagoas a mentalidade senhorial através de partidos políticos representantes do grande latifúndio na estrutura de poder. As influências do período Vargas com a inserção dos industriais no pacto de classes repercutem em Alagoas com duas décadas de atraso, dada a sua formação social periférica (SANTOS, 1982; RANGEL, 2005; SANTOS, 2008).

A formação de um expressivo operariado têxtil sob os moldes da vida urbano-industrial vai se opor a mentalidade senhorial através da formação de sindicatos, que aliado a política de Vargas, ao ampliar o direto do voto, gera transformações temporárias no quadro político alagoano. Assim, o governo Muniz Falcão (1956-1961) é um fato novo e também um enclave na história política do estado, ao exercer um governo conciliatório e institucionalizar o planejamento econômico, contrariando o interesse da oligarquia açucareira (TENÓRIO, 2007; LUEDEMANN, 2012).

Incorporando a experiência nacional e regional de planejamento, desenvolve-se uma visão global das ações do Estado. O Plano Diretor de Desenvolvimento Econômico de 1960 é o único que prevê apoio a modernização da indústria têxtil no estado, intermediando aos projetos da Sudene. A partir dessa iniciativa, coloca Alagoas como o terceiro maior captador de recursos da Superintendência (CABRAL, 2005; TENÓRIO, 2007).

\section{A INDÚSTRIA TÊXTIL SOB OS INCENTIVOS DA SUDENE}

Alcançado seu auge nos anos 1940, a indústria têxtil regional enfrenta grave crise na década seguinte, diante da integração das economias regionais seja pela redução de barreiras alfandegárias de âmbito estadual, como também, pela expansão da malha rodoviária. Com a indústria têxtil do Sudeste oriunda da pequena produção mercantil, inserida num mercado mais competitivo que estimula a modernização tecnológica, a redução no custo da produção vai resultar em tecidos mais baratos que os tecidos das fábricas nordestinas em seu próprio mercado (STEIN, 1979; MAMIGONIAN, 2009).

Buscando reverter o quadro de declínio, o Primeiro e o Segundo Plano Diretor da Sudene priorizam a indústria têxtil regional, concedendo assistência técnica e financeira, além de financiamento para o reaparelhamento das fábricas. Através da assistência técnica e financeira, visava melhorias na administração das fábricas, na qualidade da mão de obra e difusão de informações técnicas. Já através do reaparelhamento visava a modernização das fábricas de modo a reduzir os custos e aumentar sua competitividade (SUDENE, 1966a; 1966b).

Não diferente do contexto regional, as fábricas em Alagoas e Sergipe tiveram baixa adesão ao programa da Sudene. Observando a adesão das fábricas ao Fundo de Investimentos do Nordeste (Finor), quando a Sudene altera a política de incentivos fiscais, apenas uma das seis fábricas em Alagoas tem participação. Em Sergipe, a participação é de quatro das onze fábricas em operação nos anos 1970, (Tabela 2).

Tabela 2 - Projetos têxteis enquadrados no Finor até 1979 em Alagoas e Sergipe.

\begin{tabular}{cccc}
\hline UF & RELAÇAOO EMPRESAS/ESTADOS & APROVAÇĀO & LINHA DE PRODUÇÁO \\
\hline AL & Fábrica da Pedra & 1966 & $\begin{array}{c}\text { Tecidos de tergal e confecções em } \\
\text { geral }\end{array}$ \\
SE & Consórcio têxtil de acabamento S/A & 1974 & $\begin{array}{c}\text { Alvejamento ótico: tratamento } \\
\text { diversos de tecidos de algodão } \\
\text { Fios e resíduos }\end{array}$ \\
& $\begin{array}{c}\text { Grupo unido de fiação S/A - Gufi } \\
\text { Ribeiro Chaves S/A - Indústrias }\end{array}$ & 1978 & $\begin{array}{c}\text { Fraldas, tecidos de bramante, fios } \\
\text { entre outros }\end{array}$ \\
& Sergipe Industrial S/A & 1963 & $\begin{array}{c}\text { Lençóis, fronhas e sacos de algodão } \\
\text { Jeans tecido, calça jaqueta e } \\
\text { jardineira }\end{array}$ \\
\hline
\end{tabular}

Fonte - SUDENE (1979). Adaptado. 
Restritas ao algodão, a modernização dessas fábricas permitiu a utilização de fibras sintéticas como matéria-prima. Essas fibras estavam em crescente participação no mercado nacional desde a década de 1950 e permitem a fabricação de produtos mais sofisticados exigidos pelo mercado. Para a indústria têxtil regional o início dos anos 1970 é um momento de recuperação, após duas décadas de crise. Em grande medida, a modernização das fábricas locais ocorre a partir dos capitais do Sudeste, seja por iniciativa própria ou em parceira com grupos empresariais do Nordeste (CANO, 2007).

Em Sergipe, esse momento de recuperação iniciado nos anos 1970 se prolonga por mais uma década com a instalação das fábricas têxteis Nortista e do grupo Santista, esta última, no distrito industrial do município de Nossa Senhora do Socorro. Sua construção nos anos 1980 foi motivada pela saturação do distrito industrial de Aracaju e pelo crescimento urbano da capital. Atualmente o distrito industrial de Socorro é considerado o maior do estado (LACERDA, 2012; SANTOS, 2015).

Os anos 1970-80 representam um momento favorável não apenas à indústria têxtil, mas a economia do estado, com importantes obras de infraestrutura atendendo ao setor produtivo. Destaca-se nesse período o governo de Augusto Franco, responsável por grande parte destas iniciativas. Representante da família Franco, uma família tradicional no estado, é historicamente ligada à atividade têxtil, sendo proprietária da fábrica Sergipe Industrial, uma das maiores fábricas têxteis no estado (SANTOS e LEANDRO, 2010).

O período também é favorável na economia alagoana, executando importantes obras de infraestrutura e registrando as maiores taxas de crescimento do Produto Interno Bruto (PIB) desde a segunda metade do século XX. Entretanto, essa conjuntura não repercutiu na indústria têxtil local. A partir dos anos 1960, registra-se queda no número de fábricas e empregados no setor, caindo de treze fábricas e mais de dez mil empregados em 1950, para oito fábricas e aproximadamente oito mil empregados em 1960. A tendência declinante continua em 1970, chegando a seis fábricas e pouco mais de três mil empregados (IBGE, 1960, 1970; CARVALHO, 2012).

O quadro de crise e declínio da indústria têxtil em Alagoas levando a paralisação da produção e fechamento de fábricas atinge inclusive a centenária Fábrica Carmen, a maior do gênero no estado em número de empregados, produção e maquinário, com a desativação da seção de acabamento em 1972. Observa-se grande participação de grupos pernambucanos nos períodos de crise setorial, seja na aquisição do maquinário das fábricas falidas ou na compra de fábricas têxteis com o objetivo de retomar a produção (FARIAS e TAVARES, 2015; FIEA, 2018).

Apesar do aumento no número de fábricas têxteis nos anos 1980, saltando de seis para nove, o número de empregados cai quase pela metade em relação a década anterior. Isto porque as fábricas recéminstaladas são de pequeno porte, empregando poucas dezenas de trabalhadores. Estas fábricas que surgem na capital Maceió, não conseguem afirmação no mercado e já não constam no cadastro industrial da Federação das Indústrias do Estado de Alagoas (FIEA), no início dos anos 2000 (IBGE, 1984; FIEA, 2003).

Os anos 1990 representa um duro golpe ao já combalido parque têxtil alagoano por fatores de diversas escalas. A política macroeconômica nacional optando pela via importadora reduz as alíquotas de importação de diversos produtos têxteis, penalizando a indústria nacional e provocando uma enxurrada de produtos têxteis asiáticos no mercado interno. No âmbito estadual, Alagoas enfrenta a mais grave crise fiscal e econômica da história recente do estado, levando $49 \%$ de sua população economicamente ativa a desocupação, o que impacta o mercado consumidor local. Na ponta do processo produtivo, a devastação do algodão pela praga do bicudo elimina uma das poucas vantagens locacionais dessa indústria, o acesso barato a principal matéria-prima têxtil nacional (CABRAL, 2005; CARVALHO, 2012; RAULINO, 2014).

A devastação do algodão alagoano pelo bicudo é parte do problema regional de devastação das áreas tradicionais de cultivo. Baseado na pequena produção, o pouco auxílio técnico e as dificuldades de acesso ao crédito, são fatores que inviabilizaram o enfrentamento da praga e a recuperação das plantações degradadas. Essas combinações gestadas ainda no período imperial são sucedidas por novas combinações com o avanço do cultivo algodoeiro em áreas de cerrado a partir dos anos 1990. Nessa nova combinação, a predominância do fator humano se tornou definitiva com o largo emprego da técnica

$\begin{array}{lllll}\text { Caminhos de Geografia } & \text { Uberlândia-MG } & \text { v. 21, n. } 77 & \text { Out/2020 } & \text { p. 29-43 Página } 35\end{array}$


e da ciência no cultivo. Numa condição espaço-temporal diferente, as novas combinações gestadas pelo cultivo algodoeiro no cerrado recuperam a condição do país de autossuficiência na produção de algodão, além de recuperar uma grande vantagem perdida pela indústria têxtil nacional, o acesso abundante e barato as fontes de matéria-prima (CHOLLEY, 1964a; 1964b; CONAB, 2014).

Buscando reverter a estagnação econômica e retomar a capacidade de atrair novas indústrias, o governo estadual elabora o Programa de Desenvolvimento Integrado do Estado de Alagoas (Prodesin), porém, nas décadas seguintes o estado manteve a baixa capacidade em atrair indústrias. Nesse quesito, Carvalho (2012) comenta que mesmo dispondo de um moderno programa de incentivos fiscais, a baixa capacidade se mantém devido a fatores socioeconômicos como a baixa capacidade de investimento estatal e a pobreza combinada a má distribuição de renda, gerando um mercado interno restrito.

Especificamente na indústria têxtil, mesmo com o moderno programa de incentivos fiscais, para além dos fatores socioeconômicos, o estado não consegue atrair novas fábricas têxteis devido ao declínio de seu parque têxtil. Uma vez que, o setor têxtil contendo fábricas especializadas requer a presença de um parque têxtil consolidado, encadeando a produção e reforçando a vantagem locacional.

A última década representa o fim da atividade têxtil em Alagoas com o fechamento definitivo das centenárias Fábrica Carmen e Fábrica da Pedra, respectivamente em 2010 e 2017. Apesar do maquinário moderno de origem alemã com idade média de 10 anos, a Fábrica da Pedra estava com dívidas de energia elétrica e dificuldades de pagamentos com bancos e fornecedores, não resistindo a mais recente crise econômica nacional.

\section{RECUPERAÇÃO DA INDÚSTRIA TÊXTIL SERGIPANA NOS ANOS 2000}

Diante da abertura econômica nacional promovida na década anterior, as fábricas que não reagiram a mundialização da concorrência seguiram duas tendências, o encerramento de suas atividades ou a restrição a faixas limitadas de mercado, sobretudo, as de menor valor agregado. Seguindo a lógica da Terceira Revolução Industrial, as fábricas buscam adequar sua produção ao curto prazo e as constantes mudanças no padrão de consumo. Resultando em produção enxuta, redução de estoque e rápido trânsito de informações entre as unidades produtivas (CHESNAIS, 1996).

Houve reação por parte do setor têxtil através de fusões entre empresas, buscando o aprimoramento tecnológico, aumento da produtividade mediante a redução de custos e ganhos de escala, para fazer frente a concorrência com os artigos têxteis asiáticos. Em geral, essas fusões ocorreram através da aquisição de empresas em dificuldade financeira e especializadas em determinado segmento têxtil por grandes empresas. Considerando o cenário nacional, a nova realidade econômica imposta nos anos 1990 colocando a indústria nacional em condições desvantajosas gera uma nova onda de deslocamento da produção têxtil. Os segmentos mais intensivos em mão de obra se deslocam do Sudeste rumo ao Nordeste, porém, o centro de comando permanece naquela região. Esse deslocamento de segmentos da produção intensifica a especialização da produção nordestina em fiação e tecelagem.

O deslocamento vem acompanhado de intensos investimentos em modernização e concentração da produção, liderado pelo segmento de fiação, que reduziu em $73 \%$ o número de unidades fabris no Nordeste ao longo da década. Em contrapartida, houve ganho na produtividade em relação a indústria têxtil nacional, aumentando a participação da região na produção nacional de fios de $25,6 \%$ para $35,7 \%$ nos anos 1990. Na tecelagem essa participação salta de $16,3 \%$ para $23,3 \%$ no mesmo período (OLIVEIRA e CAVANCANTI, 2001).

O fim da política de desenvolvimento regional leva os estados a desenvolverem programas de incentivos fiscais, intensificando a guerra fiscal. Nesse novo ambiente econômico Alagoas desenvolve o Prodesin, destacado anteriormente, assim como Sergipe, cria o Programa Sergipano de Desenvolvimento Industrial (PSDI), em 1993, no intuito de diversificar a indústria e promover sua interiorização pelo estado (SANTOS, 2015). Ambos os programas de estimulo à industrialização são semelhantes, prevendo descontos no ICMS, doação de terrenos e apoio em infraestrutura. A experiência mostra que a guerra fiscal não tem 
sido benéfica para os estados brasileiros, sendo obrigados a abrirem mão da arrecadação tributária para atraírem empresas. Ainda assim, isoladamente os programas de incentivos e renúncias fiscais não garantem a atração de empresas. É o caso de Alagoas com relação a indústria têxtil. A criação do Prodesin não foi suficiente para atrair novas fábricas têxteis haja visto o declínio de seu parque têxtil principalmente após os anos 1980.

A partir dos anos 2000 fica evidente a diferença na trajetória que a indústria têxtil segue em ambos os estados, quando Sergipe começa a atrair grandes unidades fabris têxteis de empresas do Sudeste. Feito possibilitado pela permanência de parte de seu parque têxtil que atravessou as sucessivas crises econômicas e setoriais. A diferença de trajetória e a sutil recuperação da indústria têxtil sergipana no espaço de uma década podem ser observadas já a partir dos anos 1960 (Tabela 3), ficando notável a diferença na participação da indústria têxtil no agregado industrial de cada estado com a participação têxtil em Sergipe registrando quase o dobro em relação a Alagoas.

Tabela 3 - Participação da indústria têxtil no Valor de Transformação Industrial e pessoal ocupado no total da indústria em Alagoas e Sergipe, 1966-2015.

\begin{tabular}{ccccc}
\cline { 2 - 5 } Ano & \multicolumn{2}{c}{ ALAGOAS } & \multicolumn{2}{c}{ SERGIPE } \\
\cline { 2 - 5 } & VTI & $\begin{array}{c}\text { Pessoal } \\
\text { ocupado }\end{array}$ & VTI & $\begin{array}{c}\text { Pessoal } \\
\text { ocupado }\end{array}$ \\
\hline 1966 & 23,4 & 30,7 & 40,2 & 47,4 \\
1976 & 12,2 & 14,3 & 34,1 & 29,5 \\
1988 & 1,5 & 6,1 & 21,1 & 40,7 \\
1995 & 3,3 & 8,2 & 18,8 & 34,8 \\
2000 & 2,1 & 2,7 & 5,7 & 14 \\
2005 & 1,3 & 1,1 & 5,4 & 14 \\
2010 & 0,4 & 0,6 & 7,4 & 8,2 \\
2015 & 0,6 & 1 & 6,4 & 6,9 \\
\hline
\end{tabular}

Fonte - IBGE - Pesquisa Industrial Anual (Empresa).

Outro período de destaque ocorre entre o ano 2000 e 2010 quando a indústria têxtil sergipana registra sensível recuperação na participação do valor de transformação industrial. Por outro lado, devido a intensidade tecnológica, a participação têxtil no número de pessoal empregado na indústria mantém queda constante.

Entre os municípios mais beneficiados pelos incentivos do PSDI estão a capital Aracaju, Nossa Senhora do Socorro e Estância, que juntos concentraram $44,3 \%$ do valor adicionado da indústria sergipana em 2015. Desse modo, observa-se que a concentração na instalação das novas fábricas têxteis nos três municípios ocorreu devido à presença da atividade fabril têxtil e a concentração de outras indústrias (Figura 2), colocando os referidos municípios entre os cinco maiores geradores de recursos da atividade industrial no estado. Ainda mais, os municípios são margeados pela BR-101, principal via de acesso cortando o estado de norte a sul, fundamental na aquisição de matéria-prima e insumos, bem como, no escoamento dos produtos têxteis (SEPLAG, 2017).

Somente no espaço de dez anos, o pequeno estado nordestino recebeu investimentos para instalação de cinco fábricas têxteis, quatro delas pertencentes ao grupo Rovach, um dos maiores grupos têxteis do país. São elas, a Sergifil instalada em 2001, Aracaju Malhas, Tritex e Sergitex em instalação a partir de 2010. Além da posição geográfica favorável, o estudo de Ribeiro (2005) aponta que entre os fatores determinantes na instalação das novas fábricas no estado estão os incentivos fiscais, aliado a presença de um parque têxtil já instalado e com participação do capital local. Fatores destacados também pelo economista da Codise, comentando inclusive a importância da tradição do estado na produção têxtil e a presença de investimentos do empresariado local no setor. No revés da balança, as dificuldades que

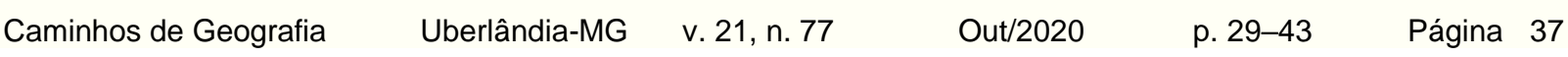


agem na atividade fabril têxtil do estado estão a distância da matéria-prima, escassez de mão de obra qualificada e de crédito barato.

Figura 2 - Localização das novas fábricas têxteis e valor adicionado da indústria dos municípios sergipanos (mil reais), 2015.

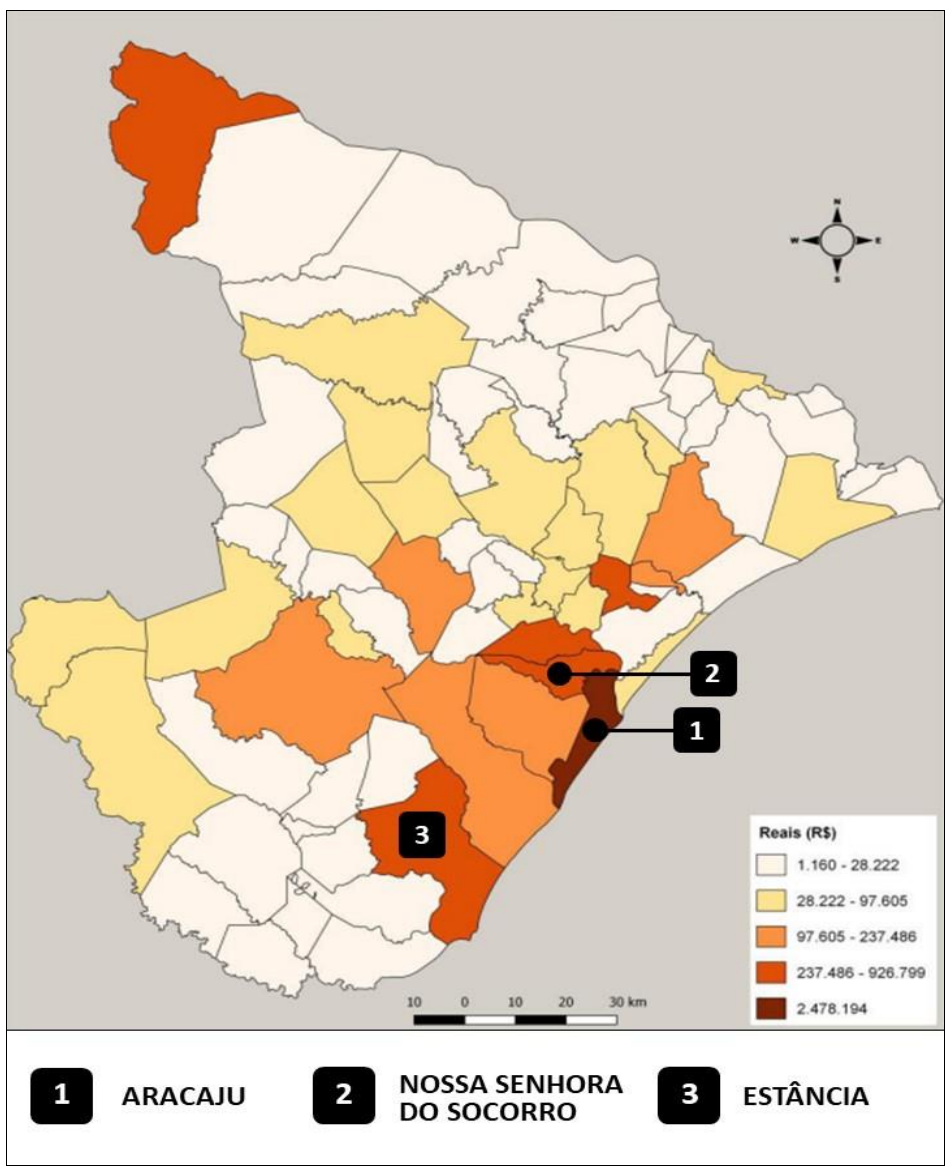

Fonte - SEPLAG-SE (2017). Adaptado.

O fortalecimento de seu parque têxtil acaba estimulando a expansão de empresas de segmentos afins, a exemplo do setor de confecções que conta com dois polos, nos municípios de Tobias Barreto e Itabaianinha, no sul do estado. No setor de energia, a instalação da Porto Sergipe I, que será a maior termoelétrica movida a gás natural na América Latina, é uma promessa na redução de custos operacionais para as indústrias do estado. Considerando que o gás natural é a segunda principal fonte de energia utilizada pela indústria têxtil brasileira, depois da eletricidade, a instalação da termoelétrica no estado é bastante conveniente para o setor têxtil local (ÉPOCA, 2018).

No último Cadastro Industrial do estado, em 2012, constam em operação treze fábricas têxteis, sendo oito delas nos municípios de Aracaju, Nossa Senhora do Socorro e Estância. Seguindo a realidade da estrutura produtiva da indústria têxtil regional, a maioria das fábricas em Sergipe operam nos segmentos de fiação e tecelagem, totalizando dez das treze fábricas em operação em 2012 (Tabela 4).

Apesar da especialização nos segmentos de fiação e tecelagem, por contar com a presença de fábricas integradas, envolvendo desde a etapa inicial de beneficiamento do algodão, Sergipe conta com um parque têxtil robusto, abrigando fábricas que demandam produtos de suas congêneres e assim encadeando a produção têxtil local. Segue este modelo, a fábrica da Altenburg, especializada na produção de travesseiros que adquire os fios das fábricas locais. De origem catarinense a unidade fabril da empresa instalada em Sergipe no ano de 2009 é a única no Nordeste, aproveitando a posição geográfica estratégica do estado para distribuir seus produtos no mercado regional. 
Tabela 4 - Fábricas têxteis em operação no estado de Sergipe, 2012.

\begin{tabular}{cccc}
\hline FÁBRICA & MUNICÍPIO & PRODUÇÃO & ORIGEM \\
\hline Altenburg Nordeste & N. S. do Socorro & Artigos de uso doméstico & Nacional \\
Atual Têxtil & Estância & Tecelagem de malha & Local \\
Fiação Itabaiana & Ribeirópolis & Fiação de algodão & Local \\
Norperola & Frei Paulo & Tecelagem de malha & Local \\
Peixoto Gonçalves & Neópolis & Tecelagem de algodão & Local \\
Santa Mônica & Aracaju & Fiação de algodão & Local \\
Sergifil & Aracaju & Fiação de algodão & Nacional \\
Sergipe Industrial & Aracaju & Artigos de uso doméstico & Local \\
Sergipe Industrial & Riachuelo & Estamparia de fios, tecidos & Local \\
Sergitex & Estância & e artigos têxteis & Nacional \\
Serrana Têxtil & Itabaiana & Fiação de algodão & Local \\
Têxtil Itatiba & N. S. do Socorro & Fiação de algodão & - \\
Tritex & N. S. do Socorro & Fiação de algodão & Nacional
\end{tabular}

Fonte - CADASTRO INDUSTRIAL DE SERGIPE (2012).

Somando-se as vantagens de Sergipe em relação a Alagoas o mercado consumidor local também tem seu peso na esfera de influência. Isto é possível dimensionar a partir dos dados que trazem um comparativo entre as faixas de rendimento da população de cada estado (Tabela 5). De imediato é observado que Alagoas possui maior parcela da população sem rendimento em relação ao estado vizinho. Além de Sergipe possuir em termos comparativos menor parcela da população na faixa 'sem rendimento', possui uma classe média mais numerosa, formando um mercado consumidor com maior potencial.

Tabela 5 - Valor do rendimento médio mensal das pessoas com 10 anos ou mais por classes de rendimento mensal, 2015.

\begin{tabular}{lcccc}
\hline \multirow{2}{*}{ CLASSES DE RENDIMENTO } & \multicolumn{2}{c}{ ALAGOAS } & \multicolumn{2}{c}{ SERGIPE } \\
\cline { 2 - 5 } & (mil pessoas) & (\%) & (mil pessoas) & (\%) \\
\hline Sem rendimento & 977 & 34,3 & 574 & 29,9 \\
Até 1/2 salário mínimo & 404 & 14,2 & 300 & 15,6 \\
Mais de 1/2 a 1 salário mínimo & 783 & 27,5 & 476 & 24,7 \\
Mais de 1 a 2 salários mínimos & 451 & 15,8 & 369 & 19,2 \\
Mais de 2 a 3 salários mínimos & 81 & 2,8 & 81 & 4,2 \\
Mais de 3 a 5 salários mínimos & 81 & 2,8 & 59 & 3,0 \\
Mais de 5 a 10 salários mínimos & 46 & 1,6 & 39 & 2,0 \\
Mais de 10 salários mínimos & 10 & 0,3 & 13 & 0,6 \\
\hline
\end{tabular}

Fonte - IBGE - Pnad (2015).

Portanto, além de Sergipe ter aproveitado melhor a guerra fiscal, soma-se desfavoravelmente a Alagoas o elevado índice de pobreza e a má distribuição de renda. Os 5\% mais pobres de Alagoas possuem o menor rendimento do país, vivendo em média com 67 reais por mês, à medida que, os $5 \%$ mais pobres em Santa Catarina, estado com maior salário do país nessa faixa de rendimento, vivem em média com 257 reais por mês. Os 5\% mais pobres de Sergipe vivem com 122 reais por mês (CARVALHO, 2012; FMI, 2017).

Foi constatado na pesquisa a entrada de produtos das fábricas têxteis de Sergipe no mercado alagoano, seja através de pequenos comerciantes e vendedores de loja de confecções que adquirem seus produtos ou através da abertura de loja de fábrica em Alagoas. É o caso da Pérola Têxtil, loja de fábrica

$\begin{array}{lllll}\text { Caminhos de Geografia } \quad \text { Uberlândia-MG } & \text { v. 21, n. } 77 & \text { Out/2020 } & \text { p. 29-43 } & \text { Página } 39\end{array}$


pertencente a Norperola (Tabela 4), comercializando tecidos de malha na principal avenida da capital Maceió desde 2010. Os poucos comerciantes de confecções do bairro de Fernão Velho, adquiriam tecidos da Fábrica Carmen ou da Fábrica da Pedra, após as falências adquirem os tecidos da fábrica sergipana Peixoto Gonçalves. A baixa margem de lucro exige deles a procura da matéria-prima mais próxima possível.

Apesar das reações verificas por parte da indústria têxtil frente a abertura econômica e a consequente mundialização da concorrência, a influência das importações asiáticas continua sendo o principal problema a ser enfrentado pelo setor. Paralelo a recuperação têxtil em Sergipe, na atual década, houve o fechamento da unidade fabril do grupo Santista no estado, sob a justificativa de estratégias internas da empresa. Nesse movimento, a empresa optou por desativar as unidades fabris no Nordeste e concentrar suas atividades em São Paulo. As fusões continuam sendo uma tendência, ocorrendo em 2010, a fusão entre o centenário grupo Constâncio Vieira e a Companhia Industrial Têxtil em Sergipe, gestando uma das maiores empresas têxteis no estado (SANTOS, 2015).

Ao que fica demonstrado, as reações da indústria têxtil não foram suficientes para fazer frente a concorrência de produtos têxteis asiáticos. O problema é causado sobretudo pelos efeitos do Plano Real que estabeleceu uma âncora cambial em relação ao dólar, onerando a competitividade industrial no mercado externo e estimulando as importações.

Para recuperar plenamente a competitividade da indústria têxtil se faz necessário retomar a política industrial, abandonada pelos governos neoliberais dos anos 1990, adotar uma medida cambial que atenda ao interesse da indústria nacional e reduzir os juros, de modo a estimular o investimento.

Por estar diretamente ligado ao consumo das famílias, a indústria têxtil é bastante sensível as oscilações da economia. Mesmo estando longe do patamar de 2010, quando a produção industrial têxtil registrou um crescimento de 6,9\%, começa a ser registrado uma lenta recuperação se comparado os índices de produção de outubro de 2018 em relação ao mesmo mês de 2017, obtendo um crescimento discreto de $0,7 \%$. A expectativa dos industriais do setor está na desvalorização cambial, condição que poderá favorecer a competitividade da indústria (ABIT, 2018).

A notável relevância da indústria têxtil para a economia de Sergipe até os dias atuais pode ser constatada no comércio e emprego. Entre o grupo da indústria de transformação, é a segunda maior exportadora no estado, perdendo apenas para a indústria de alimentos e bebidas, outra indústria tradicional do estado. Considerando o setor industrial em geral, é a quarta maior empregadora do estado (MOTA, 2014).

Tendo em vista a ausência de planos para instalação de fábricas têxteis em Alagoas e a abertura do seu mercado aos produtos têxteis de diversas origens, considerando por este ângulo, o cenário pode ser favorável às fábricas têxteis em Sergipe nos anos seguintes. Outro fator que poderá beneficiar as fábricas do estado é a retomada do cultivo algodoeiro em larga escala pelo estado do Ceará. Este que já figurou entre os maiores estados produtores de algodão no século XX, após o declínio do cultivo nos anos 1990, há planos do governo estadual para a retomada da produção. Isto aproximará as fábricas têxteis de Sergipe das fontes de matéria-prima, além de recuperar uma antiga vantagem locacional das fábricas têxteis regionais perdida naquela década.

\section{CONSIDERAÇÕES FINAIS}

O atraso relativo da indústria têxtil sergipana é compensado pelo crescimento acelerado e impulsionado pelo mercado externo até a primeira metade do século XX. Sob os incentivos da Sudene ambos os estados tiveram pouca participação nos programas de modernização, porém, em Alagoas se observa maior resistência à modernização.

$\mathrm{Na}$ cena política alagoana, a indústria têxtil consegue introduzir um representante político, ainda que indireto, nos anos 1950, período que coincide com o final do auge do setor. Contudo, considerando a história alagoana, o período de transição entre os anos 1950-60 é bastante limitado e rapidamente a elite canavieira retoma o controle político através de representantes diretos ou indiretos. A Fábrica da Pedra foi a única fábrica têxtil tradicional do estado que conseguiu aproveitar os incentivos da Sudene, mostrandose uma fábrica mais dinâmica que as congêneres locais. Não à toa, foi a última fábrica do gênero a encerrar a produção em Alagoas.

A preservação do parque têxtil em Sergipe, mantido por famílias tradicionais inseridas no quadro político do estado, foi determinante na atração de novas fábricas no início do século XXI. Evidenciando que a preservação de seu parque têxtil não foi um caso fortuito. Uma produção integrada e capaz de se

$\begin{array}{lllll}\text { Caminhos de Geografia } & \text { Uberlândia-MG } & \text { v. 21, n. } 77 & \text { Out/2020 } & \text { p. 29-43 Página } 40\end{array}$


modificar as rápidas transformações do mercado gera a necessidade das novas fábricas se instalarem em cidades sergipanas que já contam com a produção fabril têxtil.

Demandando produtos das fábricas têxteis locais, tanto as fábricas novas quanto as tradicionais, são beneficiadas pela brecha de mercado em Alagoas. Tendência que se manterá nos próximos anos por não haver planos de retomada da produção têxtil, sequer a retomada da cultura algodoeira no estado, ponta de lança do processo produtivo.

Destacando o ritmo de modernização e o interesse das classes dirigentes na trajetória industrial têxtil de ambos os estados, a pesquisa traz alguns subsídios para futuros estudos que busquem alternativas à retomada da produção industrial têxtil em Alagoas.

\section{AGRADECIMENTOS}

À Fundação de Amparo à Pesquisa do Estado de Alagoas (Fapeal), pelo auxílio financeiro, fundamental a esta pesquisa. À equipe da biblioteca da Sudene em Recife. Ao Aldo Vasconcelos, economista da Codise.

\section{REFERÊNCIAS}

ABIT - Associação Brasileira da Indústria Têxtil. Setor têxtil: empresários esperam leve recuperação após eleições. 2018. Disponível em: < http://www.abit.org.br/noticias/setor-textil-empresarios-esperamleve-recuperacao-apos-eleicoes\#>. Acesso em: 28 nov. 2018.

BRADESCO. Têxtil e confecções. Departamento de Pesquisas e Estudos Econômicos, 2017. Disponível em: <https://www.economiaemdia.com.br/EconomiaEmDia/pdf/infset_textil_e_ confeccoes.pdf>. Acesso em: 13 set. 2018.

CABRAL, L. A. P. Planos de desenvolvimento de Alagoas: 1960-2000. Maceió: Edufal, Seplan, 2005.

CANO, W. Desequilíbrios regionais e concentração industrial no Brasil 1930-1970. 3. ed. São Paulo: Unesp, 2007.

CARVALHO, C. P. Economia popular: uma via de modernização para Alagoas. 5 ed. Maceió: Edufal, 2012.

CETEX - Comissão Executiva Têxtil. Indústria têxtil algodoeira. Rio de Janeiro: CETEX, 1946.

CHOLLEY, A. Observações sobre alguns pontos de vista geográficos - parte1. Boletim Geográfico, n. 179, p. 139-145, 1964a.

Observações sobre alguns pontos de vista geográficos - parte 2. Boletim Geográfico, $\mathrm{n}$. 180 , p. 267-276, 1964b.

CONAB - Companhia Nacional de Abastecimento. Acompanhamento da safra brasileira: grãos. Observatório Agrícola, n. 8, p. 1-91, 2014.

CORRÊA, R. L. Contribuição ao estudo da área de influência de Aracaju. Revista Brasileira de Geografia, ano 27, n. 2, p. 233-258, 1965.

COSTA, A. C. R.; ROCHA, E. R. P. Panorama da cadeia produtiva têxtil e de confecções e a questão da inovação. BNDES Setorial, n. 29, 2009.

ÉPOCA. No Sergipe, Celse recebe três turbinas da GE. Revista Época, Porto Alegre, 20 jun. 2018. Disponível em: < https://epocanegocios.globo.com/Caminhos-para-o-futuro/Energia/noticia/ 2018/06/no-sergipe-celse-recebe-tres-turbinas-da-ge.html>. Acesso em: 21 jan. 2019.

FARIAS, I. S.; TAVARES, M. G. Entre o moderno e o arcaico: capitalismo e dominação na indústria têxtil de Fernão Velho (Maceió-AL). In: Seminário Internacional de Pós-Graduação em Ciências Sociais, 1., 2015, Marília. Anais... Marília: Unesp, 2015.

FIEA - Federação das Indústrias do Estado de Alagoas. Guia da indústria: Alagoas. Maceió: FIEA, 2003. CD-ROM.

Trajetória da indústria em Alagoas: 1850/2017. 1. ed. Maceió: FIEA, 2018. 
FMI - Fundo Monetário Internacional. Inequality in Brazil: a regional perspective. International Monetary Fund, 2017.

IBGE - Instituto Brasileiro de Geografia e Estatística. Censo Industrial de 1960. v. 3. t. 3. Rio de Janeiro: IBGE, 1960.

Censo Industrial de 1970. v. 4. t. 11. Rio de Janeiro: IBGE, 1970.

Censo Industrial de 1980. v. 3. n. 13. Rio de Janeiro: IBGE, 1984.

LACERDA, R. O ciclo desenvolvimentista em Sergipe: 1970-2000. Economia política do desenvolvimento, v. 5, n. 15, p. 9-68, 2012.

LUEDEMANN, M. S. Organização do espaço econômico e classes hegemônicas em Alagoas. In: Encontro Nacional de Geógrafos, 17., 2012, Belo Horizonte. Anais... Belo Horizonte: ENG, 2012.

MAMIGONIAN, A. O Nordeste e o Sudeste na divisão regional do Brasil. In: Anais de Geografia Econômica e Social. UFSC: Florianópolis, 2009.

MOTA, E. Setor industrial representa cerca de 32\% do PIB de Sergipe. Aracaju, 2014. Disponível em: $<$ http://contextoufs.com.br/?p=1539>. Acesso em: 29 abr. 2019.

OLIVEIRA, D. M., CAVALCANTI, G. A. Abertura comercial brasileira e indústria têxtil: o desempenho nacional e nordestino nos anos 90. In: TARGINO, I.; LEITE FILHO, P. A. M. (Orgs.). Nordeste: aspectos da estrutura produtiva e do mercado de trabalho. João Pessoa: Editora universitária, 2001.

PASSOS SUBRINHO, J. P. História econômica de Sergipe (1850-1930). Dissertação (Mestrado em Economia) - Campinas: Unicamp. 1983.

RANGEL, I. A história da dualidade brasileira. Revista de economia política, vol. 1, n. 4, p. 5-34, 1981.

A dinâmica da dualidade brasileira. In: BENJAMIN, C. (Org.). Obras reunidas. vol. 2. Rio de Janeiro: Contraponto, 2005, p. 552-567.

RAULINO, I. Abertura comercial, crise e reestruturação produtiva na grande empresa têxtil do médio vale do Itajaí: mitos e verdades. Cadernos Geográficos, n. 31, p. 9-104, 2014.

RIBEIRO, U. P. Política industrial e desenvolvimento regional: o caso de Sergipe no período 1995 a 2002. Dissertação (Mestrado em Geografia) - Universidade Federal de Sergipe, São Cristóvão, 2005.

SANT'ANA, M. M. Contribuição à história do açúcar em Alagoas. Edição fac-símile. Maceió: Imprensa Oficial Graciliano Ramos; Cepal. 2011.

SANTOS, C. F. A modernidade chega de trem: o progresso como discurso para o advento dos caminhos de ferro no Estado de Sergipe. In: Seminário Regional Norte-Nordeste de Pós-Graduação em Geografia SERNNE, 2., 2015, João Pessoa. Anais... João Pessoa: UFPB, 2012.

SANTOS, D. W. S.; LEANDRO, H. W. S. "Grandes Famílias" e estruturação do espaço do poder em Sergipe: Reconversões sociais e esferas de atuação. Scientia Plena, v. 6, n. 12, p. 1-18, 2010.

SANTOS, H. F. Industrialização e o desenvolvimento econômico do município de Estância (SE): 2002 a 2012. Dissertação (Mestrado em Economia) - Universidade Federal de Sergipe, São Cristóvão, 2015.

SANTOS, M. Espaço e sociedade. 2. ed. Petrópolis: Vozes, 1982. Edusp, 2008.

Por uma geografia nova: da crítica da geografia a uma geografia crítica. 6. ed. São Paulo:

SEPLAG-SE - Secretaria de Planejamento, Orçamento e Gestão de Sergipe. Produto Interno Bruto dos municípios de Sergipe: 2015. Aracaju, 2017. Disponível em: <http://www.observatorio.se.gov.br/images/PIB_Municipal/ PIB_2013_dos_munic\%C3\%

ADpios_final_21.12.2015.pdf.>. Acesso: 04 dez. 2018.

STEIN, S. J. Origens e evolução da indústria têxtil no Brasil 1850-1950. 1. ed. Rio de Janeiro: Editora Campus, 1979.

SUDENE - Superintendência do Desenvolvimento Econômico do Nordeste. Plano Diretor do Desenvolvimento do Nordeste I 1961-1963. 2. ed. Recife: Sudene, 1966a.

Plano Diretor do Desenvolvimento do Nordeste Il 1963-1965. 2. ed. Recife: Sudene, $1966 \mathrm{~b}$.

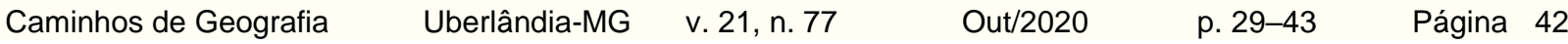


TENÓRIO, D. A. A tragédia do populismo: o impeachment de Muniz Falcão. 2. ed. Maceió: Edufal, 2007.

TENÓRIO, D. A.; LESSA, G. L. O ciclo do algodão e as vilas operárias. 1. ed. Maceió: Edufal, 2013.

Recebido em: 11/06/2019

Aceito para publicação em: 14/09/2020 